\title{
Dutch nOcturnal and hoME dialysis Study To Improve Clinical Outcomes (DOMESTICO): rationale and design
}

A. van Eck van der Sluijs ${ }^{1 \dagger}$, A. A. Bonenkamp ${ }^{2 \dagger}$, F. W. Dekker ${ }^{3}$, A. C. Abrahams ${ }^{1}$, B. C. van Jaarsveld ${ }^{2,4^{*}}$ and on behalf of the DOMESTICO study group

\begin{abstract}
Background: More than 6200 End Stage Renal Disease patients in the Netherlands are dependent on dialysis, either performed at home or in a dialysis centre. Visiting a dialysis centre three times a week is considered a large burden by many patients. However, recent data regarding the effects of dialysis at home on quality of life, clinical outcomes, and costs compared with in-centre haemodialysis are lacking.

Methods: The Dutch nOcturnal and hoME dialysis Study To Improve Clinical Outcomes (DOMESTICO) is a nationwide, prospective, observational cohort study that will include adult patients starting with a form of dialysis. Health-related quality of life, as the primary outcome, clinical outcomes and costs, as secondary outcomes, will be measured every 36 months in patients on home dialysis, and compared with a control group consisting of in-centre haemodialysis patients. During a 3-year period 800 home dialysis patients (600 peritoneal dialysis and 200 home haemodialysis patients) and a comparison group of 800 in-centre haemodialysis patients will be included from 53 Dutch dialysis centres (covering 96\% of Dutch centres) and 1 Belgian dialysis centre (covering 4\% of Flemish centres).
\end{abstract}

Discussion: DOMESTICO will prospectively investigate the effect of home dialysis therapies on health-related quality of life, clinical outcomes and costs, in comparison with in-centre haemodialysis. The findings of this study are expected to ameliorate the shared decision-making process and give more guidance to healthcare professionals, in particular to assess which type of patients may benefit most from home dialysis.

Trial registration: The DOMESTICO study is registered with the National Trial Register on (number: NL6519, date of registration: 22 August 2017) and the Central Committee on Research Involving Human Subjects (CCMO) (number: NL63277.029.17).

Keywords: Clinical outcomes, Costs, Health-related quality of life, Home dialysis, Home haemodialysis, In-Centre haemodialysis, Peritoneal dialysis

\section{Background}

In the Netherlands, over 6200 patients with End Stage Renal Disease (ESRD) are dependent on dialysis, and over the past 15 years, the number of dialysis patients has increased by more than $20 \%[1-3]$. The burden of dialysis is high and the health-related quality of life

\footnotetext{
* Correspondence: b.jaarsveld@amsterdamumc.nl

${ }^{+}$A. van Eck van der Sluijs and A. A. Bonenkamp contributed equally to this work.

${ }^{2}$ Department of Nephrology, Amsterdam University Medical Centers, Vrije Universiteit Amsterdam, Amsterdam, The Netherlands

${ }^{4}$ Diapriva Dialysis Center, Amsterdam, The Netherlands

Full list of author information is available at the end of the article
}

(HRQoL), which is presently considered to be the most important outcome parameter in dialysis patients, is much worse than that of healthy people [4]. As patient survival is poor, with a median five-year survival rate of only $45 \%$, optimising HRQoL is of great importance for this growing group of patients $[5,6]$.

Besides its impact on HRQoL, dialysis is also an expensive treatment. In the Netherlands, the estimated costs are approximately 570 million euro per year (639 million US dollars) and are still increasing. [Personal communications, G.A. De Wit, National Institute for Public Health and the Environment, 2019] This makes

(c) The Author(s). 2019 Open Access This article is distributed under the terms of the Creative Commons Attribution 4.0 International License (http://creativecommons.org/licenses/by/4.0/), which permits unrestricted use, distribution, and 
dialysis by far the highest cost-consuming treatment in internal medicine, not only calculated per individual patient, but also if total treatment costs are taken into account [7].

Home dialysis has a potential positive effect on HRQoL because it offers flexibility to patients and greater freedom [8]. Moreover, home dialysis is possibly a more cost-effective therapy if less nursing staff is needed, when patients perform their treatment autonomously or with help of an informal caregiver. Despite these potential advantages, currently more than $80 \%$ of dialysis patients are treated with in-centre haemodialysis (ICHD). Furthermore, the percentage of patients treated with home dialysis is steadily decreasing in the Netherlands, from $32 \%$ in 2002 to $18 \%$ in 2018. This decline is mainly attributable to a reduction in the number of patients performing peritoneal dialysis (PD), the main home based therapy, with 1519 PD patients (30\% of total dialysis patients) in 2002 versus 894 PD patients (14\% of total dialysis patients) in 2018 [1].

Available evidence regarding the effects of home dialysis compared with ICHD on HRQoL, a Patient Reported Outcome (PRO), is limited. Most studies have a crosssectional design and lack adequate correction for confounding among dialysis groups [9-38]. Also, the characteristics of patients starting with some kind of home dialysis treatment have changed remarkably over the past years. Previously, those patients were typically young, working people with little comorbidities, whereas during the last years the general home dialysis population is older and often suffers from multiple comorbidities [2]. This could influence clinical outcomes such as mortality and hospitalisation rate. Finally, there are limited data available regarding the cost-effectiveness of home dialysis.

To investigate the effect of home dialysis on HRQoL, clinical outcomes, and costs, the Dutch nOcturnal and hoME dialysis Study To Improve Clinical Outcomes (DOMESTICO) has been initiated. The aim of this study is to compare HRQoL, clinical outcomes, and cost-effectiveness of home dialysis with ICHD. The hypothesis is that home dialysis is associated with better HRQoL, at least comparable clinical outcomes and lower costs, compared to ICHD.

\section{Methods}

\section{Study design}

DOMESTICO is a nationwide, prospective, observational cohort study comparing home dialysis with ICHD. The maximum follow-up period of the study is 48 months. At present, 53 Dutch dialysis centres (covering 96\% of Dutch centres) and 1 Belgian dialysis centre have agreed to recruit patients (Fig. 1). The study is conducted according to the principles of the Declaration of Helsinki

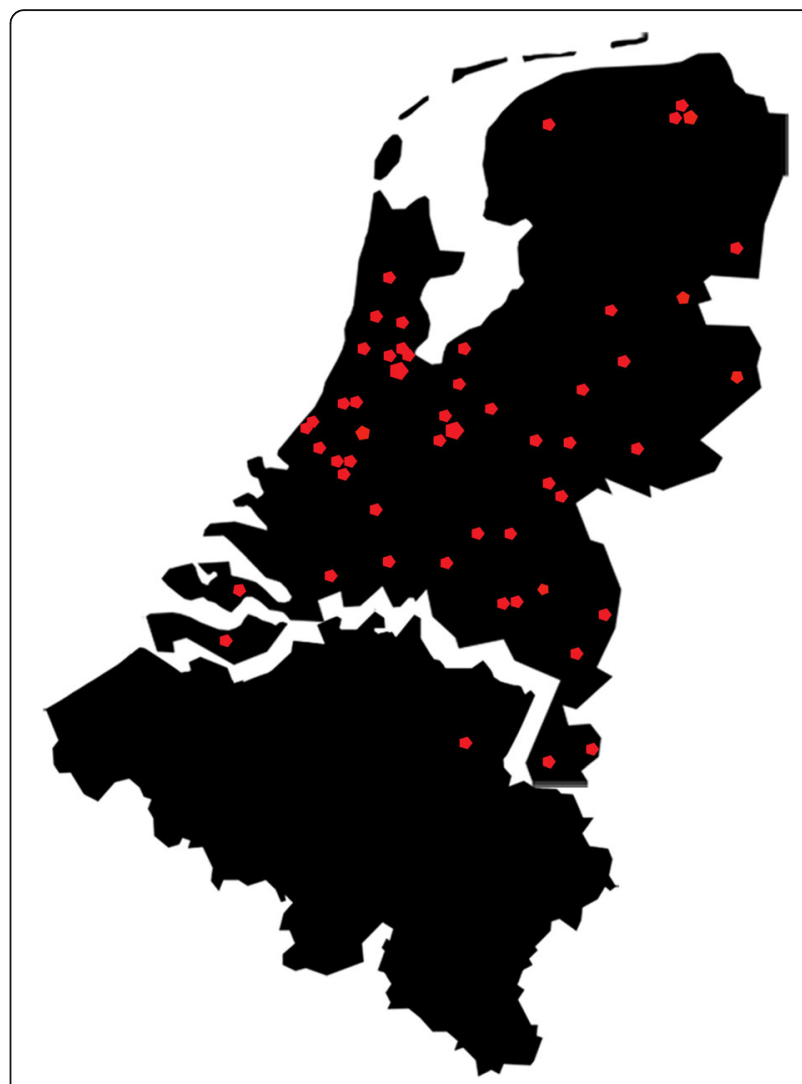

Fig. 1 Participating centres. The red dots indicate the participating centres: 53 Dutch dialysis centres (covering 96\% of Dutch centres) and 1 Belgian dialysis centre

and in accordance with the Medical Research Involving Human Subjects Act (WMO).

\section{Study population}

All patients, aged 18 years and older, with ESRD that start with a form of dialysis in the participating centres, between December 2017 and December 2020, are eligible for this study. These patients are allowed to have a history of renal replacement therapy (RRT), however they have to (re) start dialysis during the study period for example due to kidney transplant failure (with or without previous dialysis). All these patients are defined as 'incident patients'. Prevalent dialysis patients, and patients with a life expectancy shorter than 3 months or an expected kidney transplantation within 3 months, are excluded. Patients have to provide written informed consent before participating in the study.

\section{Inclusion}

Patients are included in the period within four weeks before to four weeks after start of dialysis. If patients are missed for inclusion within this timeframe (for example, due to acute start of dialysis), they can be included at 3 months ( \pm 2 weeks) after start of dialysis. Start of dialysis 
is defined as the first PD session performed at (a nursing) home (excluding PD-training) or, in case of ICHD, the first haemodialysis session performed in a centre (excluding continuous RRT).

The first patient was included in December 2017 and the study has currently started in 45 centres with 338 participating patients (Fig. 2).

\section{(Early) termination}

For each participating patient, the study ends on 20 December 2021. Early study termination occurs if the patient withdraws from the study or stops dialysis treatment. Reasons to stop dialysis include kidney transplantation, recovery of kidney function, the wish to stop dialysis, or death.

\section{Outcomes}

\section{Primary outcome parameter}

The primary outcome parameter is the patient's HRQoL, a PRO, determined with the 12-item Short Form (SF-12) health survey and the Dialysis Symptom Index (DSI) $[39,40]$. These questionnaires were carefully selected as Patient Reported Outcome Measures (PROMs) in nephrological care by the Dutch Kidney Patients Association, the Dutch Federation for Nephrology, Nefrovisie (the Dutch Quality Institute for Nephrology), and Leiden University Medical Center [41, 42].

The SF-12 is the shorter version of the Short Form36 (SF-36), one of the most widely used surveys to assess HRQoL [43, 44]. The SF-36 consists of eight domains: Physical functioning, Role-physical, Bodily pain, General health, Vitality, Social function, Roleemotional and Mental health. These domains are summarised in the Physical Component Summary (PCS) score and the Mental Component Summary (MCS) score. In the SF-12 these summary scores are calculated from the 12 most important questions (explaining 90\% variance) of the SF-36 questionnaire $[39,45]$. As the average difference in summary scores

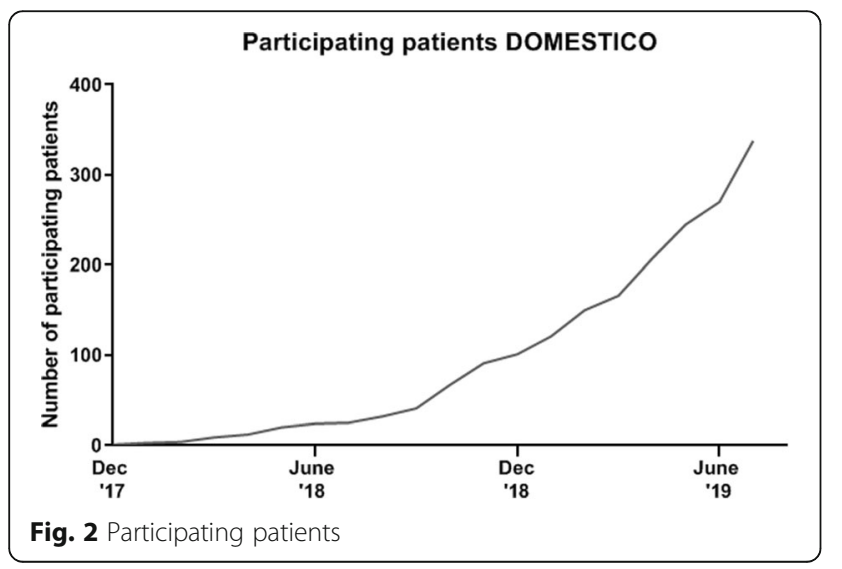

between SF-36 and SF-12 is quite small, for time-efficiency reasons, the SF-12 can be used reliably in cohort studies [46].

The DSI consists of 30 questions evaluating the severity of symptoms relevant to dialysis and ESRD patients (Table 1). Patients report the level of burden of specific symptoms on a 5-point Likert scale, options range from 'not at all bothersome' to 'very bothersome' [40].

\section{Secondary outcome parameters}

Secondary outcome parameters are hospitalisation, mortality, other clinical parameters, costs, and technique failure.

The cause of each hospitalisation episode will be categorised into the following categories (using ICD-10 codes) [47]:

- Cardiac (including myocardial ischaemia/infarction, cardiac arrest/arrhythmia, cardiac failure, fluid overload/pulmonary edema, haemorrhagic pericarditis);

- Vascular disease (including pulmonary embolus, stroke, cerebrovascular haemorrhage, ruptured vascular aneurysm, mesenteric infarction, peripheral arterial disease);

- Infection, non-dialysis related (including bacteraemia/sepsis, cardiac infection, HIV, osteomyelitis, respiratory infection, urinary tract infection);

Table 1 Items Dialysis Symptom Index

\begin{tabular}{ll}
\hline 1. Constipation & 16. Chest pain \\
2. Nausea & 17. Headache \\
3. Vomiting & 18. Muscle soreness \\
4. Diarrhoea & 19. Difficulty concentrating \\
5. Decreased appetite & 20. Dry skin \\
6. Muscle cramps & 21. Itching \\
7. Swelling in legs & 22. Worrying \\
\begin{tabular}{ll} 
8. Shortness of breath & 23. Feeling nervous \\
9. Lightheadedness or dizziness & 24. Trouble falling asleep \\
10. Restless legs or difficulty & 25. Trouble staying asleep \\
keeping legs still & 26. Feeling irritable \\
$\begin{array}{ll}\text { 11. Numbness or tingling } \\
\text { in feet }\end{array}$ & 27. Feeling sad \\
$\begin{array}{ll}\text { 12. Feeling tired or lack of } \\
\text { energy }\end{array}$ & 28. Feeling anxious \\
13. Cough & 29. Decreased interest in sex \\
14. Dry mouth & 30. Difficulty becoming \\
15. Bone or joint pain & sexually aroused \\
\hline
\end{tabular}
\end{tabular}


- Dialysis related (including dialysis access infection, peritonitis, PD catheter leakage/exchange/removal, fistula operation, renal fluid overload, bleeding);

- Malignancy;

- Bleeding, non-dialysis related (including intracranial bleeding, gastro-intestinal bleeding, other causes of bleeding);

- Other causes.

Mortality will be categorised into the following categories (using ERA-EDTA codes) [48]:

- Sudden death 'with unknown cause';

- Cardiac (including myocardial ischaemia/infarction, cardiac arrest/arrhythmia, cardiac failure, fluid overload/pulmonary edema, haemorrhagic pericarditis);

- Vascular (including pulmonary embolus, stroke, cerebrovascular haemorrhage, ruptured vascular aneurysm, mesenteric infarction, peripheral arterial disease);

- Infectious, dialysis related (including dialysis access infection, peritonitis);

- Infectious, non-dialysis related (including bacteraemia/sepsis, cardiac infection, HIV, osteomyelitis, respiratory infection, urinary tract infection);

- Malignancy;

- Bleeding (including dialysis related bleeding, intracranial bleeding, gastro-intestinal bleeding, other causes of bleeding);

- Overall deterioration in clinical condition/stopping dialysis;

- Other causes.

Besides hospitalisation and mortality, several clinical parameters will be recorded including blood pressure and use of antihypertensive drugs, haemoglobin and use of erythropoiesis-stimulating agents, phosphate levels and use of phosphate binders, vascular access parameters, and nutritional status.

Direct healthcare costs, patient costs, and costs with regard to productivity losses will be assessed with a subset of questions from the Institute for Medical Technology Assessment (iMTA) Productivity Cost Questionnaire (iPCQ) and the iMTA Medical Cost Questionnaire (iMCQ) $[49,50]$. To capture all health care costs for the population under research a small number of disease specific services are added to the standard $\mathrm{iMCQ}$, e.g. home dialysis. Given the fact that many patients need substantial help from close relatives, also use of informal care by patients will be assessed. The costs related to the healthcare consumption, the dialysis procedures, the diagnostic tests and (over-the-counter) medication will be derived from the patient's medical chart during the study. Unit costs will be derived from the Dutch manual for costing studies [51].

To further examine cost-effectiveness, the EuroQol-5D5L (EQ5D-5L) questionnaire will be used. The EQ-5D-5L measures HRQoL on the following 5 domains: mobility, self-care, usual activities, pain/discomfort, and anxiety/depression. Each domain has 5 levels of functioning, ranging from 'no problems' to 'extreme problems'. The EQ-5D-5L also contains a visual analogue scale on which the current health state can be indicated. The EQ-5D scores can be used to calculate utilities, which describe HRQoL on a scale from 0 (dead) to 1 (perfect health). Utilities can be combined with survival to calculate quality adjusted life years (QALYs). As outcome measure for cost-effectiveness, the costs per additional QALY will be analysed [52, 53].

All participating patients will also receive a self-management screening questionnaire (SeMaS) at baseline, in order to investigate whether self-management can predict a successful home dialysis treatment. This questionnaire shows the abilities and possible barriers for selfmanagement by asking questions about the burden of disease, locus of control, self-efficacy, social support, coping style, anxiety, depression, and skills [54, 55].

Table 2 provides an overview of the moments when participating patients will fill in the aforementioned questionnaires.

Finally, technique failure rate of home dialysis, defined by a composite outcome of death or transfer to ICHD, will be assessed. Both a 30-days and a 180-days definition of technique failure will be used according to the minimum number of days the patient received ICHD after cessation of home dialysis [56]. Permanent technique failure is defined by death or transfer to ICHD (using the 180-days definition), or cessation of dialysis. Death-censored technique failure will be reported separately. Transfer to kidney transplantation is not considered to be technique failure and will also be reported separately [56].

Table 2 Overview questionnaires

\begin{tabular}{lllll}
\hline Visit & $\begin{array}{l}\text { SF-12 } \\
\text { and DSI }\end{array}$ & $\begin{array}{l}\text { iPCQ } \\
\text { and iMCQ }\end{array}$ & EQ-5D-5L & SeMaS \\
\hline Baseline & $X$ & $X$ & $X$ & $X$ \\
At 3 and 6 months & $X$ & $X$ & $X$ & \\
$\begin{array}{l}\text { At } 9 \text { months and every } \\
6 \text { months thereafter }\end{array}$ & & $X$ & & \\
$\begin{array}{l}\text { At } 12 \text { months and } \\
\text { every } 6 \text { months thereafter }\end{array}$ & $X$ & $X$ & $X$ & \\
\hline
\end{tabular}

SF-12 Short Form-12, DSI Dialysis Symptom Index, iPCQ Institute for Medical Technology Assessment (iMTA) Productivity Cost Questionnaire, iMCQ iMTA Medical Cost Questionnaire, SeMaS self-management screening questionnaire 


\section{Data collection}

All study outcomes, except the SeMaS, will be assessed at baseline, after 3 months, 6 months, and thereafter every 6 months until end of follow-up or end of the study (Table 2).

Data will be registered in case report forms (CRF). IBM Data Collection will be used as CRF. The database is developed by Nefrovisie and follows the principles of Good Clinical Practice (i.e. it has an audit trail, possibility for electronic signing, direct validation of inserted data, authorisation per form and user). Nefrovisie will also host the database for the duration of the study. The database will be archived for future research during 15 years after termination of the study.

\section{Statistical analysis}

All statistical analyses will be performed using statistical software such as SPSS and Stata. Univariable and multivariable regression analysis will be conducted. In case of repeated measures, multilevel analysis or generalised estimating equations will be applied. Possible confounders determined a priori are age, gender, marital status, level of education, work status, cause of renal failure, prior RRT with dialysis vintage, comorbidities, albumin, body mass index, and protein energy wasting. Cumulative incidence of hospitalisation, mortality, and technique failure will be reported in Kaplan Meier curves. In case of missing data, multiple imputation techniques will be used to impute the missing values where appropriate.

Overall costs will be compared across the treatment groups and 95\% confidence intervals will be estimated using bootstrapping techniques. The cost-effectiveness of different dialysis modalities will be determined using a state transition model. This model captures the changes in treatment modality, including transplantation, over time. The results of the DOMESTICO study will be used as input parameters for this model.

\section{Sample size calculation}

For the primary outcome HRQoL, obtained with the SF12 , a sample size of 350 patients is required. To obtain a clinically relevant difference between groups of 3 points in the SF-12 summary scores, after a median of 12 months follow-up, 175 patients per group are needed (assumed standard deviation $=10$ points, $\alpha=0.05, \beta=$ $0.20)[46,57-59]$.

However, for the EQ5D-5L, an important component for the secondary outcome cost-effectiveness, a sample size of 1400 patients (700 patients per group) is needed. A difference of $0.03-0.07$ points between groups after a mean follow-up of 12 months is considered clinically relevant $[44,60,61]$. The standard deviation in dialysis groups ranges from 0.1 to 0.22 [62, 63]. Assuming a common standard deviation of 0.20 and the lowest, still clinically relevant score, a total of 1400 patients (700 patients per group) will be sufficient to detect a difference of 0.03 points in the EQ5D-5L score between groups $(\alpha=0.05, \beta=0.20)$.

When approximately $10 \%$ loss to follow up is taken into account, a group of 800 home dialysis patients and a comparison group of 800 ICHD patients has to be included in order to have sufficient power to analyse both outcomes. Since the ratio between PD patients and home haemodialysis (HHD) patients in the Netherlands is expected to be 3:1 in future years, the home dialysis group will consist of 600 PD and 200 HHD patients.

\section{Discussion}

Dialysis has a great impact on the HRQoL of ESRD patients and dialysis is a very expensive treatment. More than $80 \%$ of Dutch dialysis patients are treated with ICHD although home dialysis could result in a better HRQoL and could be more cost effective. Therefore, we initiated the DOMESTICO study, which will investigate the effects of home dialysis on HRQoL in relation to clinical outcomes and costs, in comparison with ICHD. This nationwide cohort study will include 1600 incident dialysis patients over a period of 3 years. At time of submission of this manuscript, 338 patients have been included.

Although a randomised controlled trial (RCT) would yield the ultimate answer to our research question, this is not in accordance with the concept of shared decision making. A patient's choice between home dialysis and ICHD is considered too fundamental, to let it be determined by chance. Indeed, an RCT in the Netherlands comparing PD with ICHD conducted in the past, stopped early due to poor patient recruitment; only 38 patients consented to be randomly assigned to either PD or ICHD [64]. Hence, DOMESTICO is designed as a prospective, observational cohort study collecting extensive parameters to correct for confounding by indication.

The results of this study will be of great importance for future ESRD patients when choosing a treatment, as HRQoL is increasingly acknowledged by clinicians and patients as an important aspect in the decisionmaking process. In addition, the results with respect to clinical outcomes will ameliorate the shared decision-making process. Finally, the data could give more guidance to healthcare professionals, in particular to assess which type of patients may benefit most from home dialysis. 


\section{Additional file}

Additional file 1: Local ethics committees/IRBs DOMESTICO. This file contains a list of the 44 (out of 53) local ethics committees from which approval for DOMESTICO is obtained. (DOCX $17 \mathrm{~kb}$ )

\begin{abstract}
Abbreviations
CCMO: Central Committee on Research Involving Human Subjects; CRF: Case report forms; DOMESTICO: Dutch nOcturnal and hoME dialysis Study To Improve Clinical Outcomes; DSI: Dialysis Symptom Index; EQ5D-5L: EuroQol5D-5L; ESRD: End Stage Renal Disease; HHD: Home haemodialysis; HRQOL: Health-related quality of life; ICHD: In-centre haemodialysis; iMCQ: iMTA Medical Cost Questionnaire; iMTA: Institute for Medical Technology Assessment; iPCQ: iMTA Productivity Cost Questionnaire; MCS: Mental Component Summary; PCS: Physical Component Summary; PD: Peritoneal dialysis; PRO: Patient Reported Outcome; PROM: Patient Reported Outcome Measure; QALY: Quality adjusted life year; RCT: Randomised controlled trial; RRT: Renal replacement therapy; SeMaS: Self-management screening questionnaire; SF: Short Form
\end{abstract}

\section{Acknowledgements}

Not applicable.

\section{DOMESTICO committee members and investigators}

\section{Committee members}

Steering committee: AC Abrahams, University Medical Center Utrecht; BC van Jaarsveld, Amsterdam University Medical Centers (VU University, Amsterdam) and Diapriva Dialysis Center Amsterdam; FW Dekker, Leiden University Medical Center; A van Eck van der Sluijs, University Medical Center Utrecht; AA Bonenkamp, Amsterdam University Medical Centers (VU University, Amsterdam); MC Verhaar, University Medical Center Utrecht; FJ van Ittersum, Amsterdam University Medical Centers (VU University, Amsterdam); JAJ Bart, Dutch Kidney Patients Association (NVN); MH Hemmelder, Nefrovisie and Medical Center Leeuwarden.

DOMESTICO prospective 'Quality of life and clinical outcomes' committee: AC Abrahams, University Medical Center Utrecht; BC van Jaarsveld, Amsterdam University Medical Centers (VU University, Amsterdam) and Diapriva Dialysis Center Amsterdam; FW Dekker, Leiden University Medical Center; A van Eck van der Sluijs, University Medical Center Utrecht; AA Bonenkamp, Amsterdam University Medical Centers (VU University, Amsterdam); FJ van Ittersum, Amsterdam University Medical Centers (VU University, Amsterdam); JAJ Bart, Dutch Kidney Patients Association (NVN); EL Penne, Northwest Clinics Alkmaar; DG Struijk, Dianet Amsterdam and Amsterdam University Medical Centers (location AMC); A Özyilmaz, University Medical Center Groningen and Dialysis Center Groningen.

DOMESTICO prospective 'Costs' committee: AC Abrahams, University Medical Center Utrecht; BC van Jaarsveld, Amsterdam University Medical Centers (VU University, Amsterdam) and Diapriva Dialysis Center Amsterdam; A van Eck van der Sluijs, University Medical Center Utrecht; AA Bonenkamp, Amsterdam University Medical Centers (VU University, Amsterdam); MM Versteegh, Institute for Medical Technology Assessment; L Hakkaart-van Roijen, Institute of Health Policy \& Management and Institute for Medical Technology Assessment; GA de Wit, Julius Center for Health Sciences and Primary Care; FT Boereboom, Dianet Utrecht and Diakonessenhuis; MH Hemmelder, Nefrovisie and Medical Center Leeuwarden, TA Kanters, Institute for Medical Technology Assessment; G de Graaf, Institute for Medical Technology Assessment.

Investigators

P Leurs, Admiraal de Ruyter Hospital Goes; MR Korte, Albert Schweitzer Hospital Dordrecht; AM Schrander, Alrijne Hospital; TT Cnossen, Amphia Hospital Breda; BC van Jaarsveld, Amsterdam University Medical Centers (VU University, Amsterdam) and Diapriva Dialysis Center Amsterdam; J Lips, Bernhoven Uden; HP Krepel, Bravis Hospital Roosendaal; MAGJ ten Dam, Canisius-Wilhelmina Hospital Nijmegen; CJAM Konings, Catharina Hospital Eindhoven; CJ Doorenbos, Deventer Hospital; A Lips, Dialysiscenter Beverwijk; A Özyilmaz, Dialysis Center Groningen; DG Struijk and FTJ Boereboom, Dianet Amsterdam and Utrecht; S van Esch, Elisabeth-TweeSteden Hospital Tilburg; CR Susanto, Elkerliek Hospital; GF van Breda, Elyse Clinics; EJ Hoorn and D Severs, Erasmus Medical Center Rotterdam; AH Boonstra, Flevohospital Almere; RW Nette, Franciscus Gasthuis \& Vlietland Rotterdam; YM Vermeeren, Gelre Hospitals Apeldoorn; DHT ljpelaar, Groene Hart Hospital Gouda; HD Thang and NH
Hommes, Haaglanden Medical Center The Hague; M van Buren, HagaHospital The Hague; JM Hofstra, Hospital Gelderse Vallei Ede; SHA Diepeveen, Isala Zwolle; EK Hoogeveen, Jeroen Bosch Hospital 's-Hertogenbosch; T Cornelis, Jessa Hospital Hasselt (Belgium); S Boorsma, Laurentius Hospital Roermond; J Rotmans, Leiden University Medical Center; AM van Alphen, Maasstad Hospital Rotterdam; F van der Sande and EJR Litjens, Maastricht UMC+; WMT Janssen, Martini Hospital Groningen; A Kuijper and CH Beerenhout, Máxima Medical Center Veldhoven; MH Hemmelder, Medical Center Leeuwarden; HS Brink and R Wijering, Medical Spectrum Twente Enschede; RJ Bosma, Niercentrum Midden Nederland Amersfoort; EL Penne, Northwest Clinics Alkmaar; CWH de Fijter and HFH Brulez, OLVG Amsterdam; HW van Hamersvelt, Radboudumc Nijmegen; SJ Huisman, Reinier de Graaf Gasthuis Delft; MP Kooistra and JC Verhave, Rijnstate Arnhem; G van Kempen, Saxenburgh Group; H Klein, Slingeland Hospital Doetinchem; CE Douma, Spaarne Gasthuis Hoofddorp; HH Vincent and WJW Bos, St. Antonius Hospital Nieuwegein; JD Snoep, Tergooi Hilversum; J Mulder, Treant Zorggroep Emmen; CFM Franssen, University Medical Center Groningen; AC Abrahams, University Medical Center Utrecht; AJ Luik, VieCuri Medical Center Venlo; RJL Klaassen, Zaans Medical Center Zaandam; AG Weenink, ZorgSaam Hospital Terneuzen; MME Krekels, Zuyderland Sittard.

\section{Authors' contributions}

$A E S$ and $A A B$ contributed equally to this article. $B C J, A C A, F W D$ and $A A B$ designed the protocol of the present study. BCJ, ACA, FWD, AES and $A A B$ are all involved in the conductance of the study. All authors critically edited the manuscript and approved the final version.

\section{Funding}

This study is supported by grants of ZonMw, Fresenius Medical Care Deutschland $\mathrm{GmbH}$, Baxter Netherlands BV, and Dirinco. The grant of ZonMw is provided from the 'Health care efficiency research' programme and focusses on the part of this study concerning health-related quality of life. ZonMw has independently peer reviewed the study protocol. With the Fresenius Medical Care Deutschland GmbH grant, clinical outcomes will be investigated, and the grant of Baxter focusses on costs and cost-effectiveness. The sponsors did not play a role in the study design and the preparation of this article.

\section{Availability of data and materials}

Not applicable.

\section{Ethics approval and consent to participate}

Primary ethical approval was obtained from the medical research ethics committee of the VU University Medical Center Amsterdam, on December 7th 2017 (reference number: 2017.491, NL63277.029.17). Central approval for 53 participating centres has been obtained from the medical research ethics committee of the VU University Medical Center. Local approval has been obtained from 44 out of 53 local ethics committees. Additional file 1 contains a list of these local committees. For any future centres which will be included in our study, additional ethical approval will be sought. For the Belgium centre, ethical approval has been obtained from the ethics committee of Jessa Hospital (reference number: 18.19/nefro18.01).

\section{Consent for publication}

Not applicable.

\section{Competing interests}

Fresenius Medical Care Deutschland GmbH, Baxter Netherlands BV, and Dirinco support the work of all authors.

\section{Author details}

${ }^{1}$ Department of Nephrology and Hypertension, University Medical Center Utrecht, Utrecht, The Netherlands. ²Department of Nephrology, Amsterdam University Medical Centers, Vrije Universiteit Amsterdam, Amsterdam, The Netherlands. ${ }^{3}$ Department of Clinical Epidemiology, Leiden University Medical Center, Leiden, The Netherlands. ${ }^{4}$ Diapriva Dialysis Center, Amsterdam, The Netherlands. 


\section{Received: 16 July 2019 Accepted: 16 August 2019}

\section{Published online: 18 September 2019}

\section{References}

1. Nefrovisie. http://www.nefrovisie.nl/nefrodata/. Accessed 20 June 2019

2. Hemke AC, Dekker FW, Bos WJW, et al. Oorzaken voor verminderd aandee peritoneale dialyse als nierfunctievervangende behandeling in Nederland. Ned Tijdschr Geneeskd. 2012;156:1-8.

3. Volksgezondheidenzorg.info. https://www.volksgezondheidenzorg.info/. Accessed 2 May 2019.

4. Gorodetskaya I, Zenios S, McCulloch CE, et al. Health-related quality of life and estimates of utility in chronic kidney disease. Kidney Int. 2005;68:2801-8.

5. van de Luijtgaarden MWM, Jager K, Segelmark M, et al. Trends in dialysis modality choice and related patient survival in the ERA-EDTA registry over a 20-year period. Nephrol Dial Transplant. 2016;31:120-8.

6. Kramer A, Pippias M, Noordzij M, et al. The European renal association - European Dialysis and transplant association (ERA-EDTA) registry annual report 2015: a summary. Clin Kidney J. 2018;11(1):108-22.

7. Nederlandse Zorgautoriteit. http://opendisdata.nl/. Accessed 2 May 2019

8. Ageborg M, Allenius BL, Cederfjall C. Quality of life, self-care ability, and sense of coherence in hemodialysis patients: a comparative study. Hemodial Int. 2005:9:58-14.

9. Al Wakeel J, Al Harbi A, Bayoumi M, et al. Quality of life in hemodialysis and peritoneal dialysis patients in Saudi Arabia. Ann Saudi Med. 2012;32(6):570-4.

10. Atapour A, Nasr S, Boroujeni AM, et al. A comparison of the quality of life of the patients undergoing hemodialysis versus peritoneal dialysis and its correlation to the quality of dialysis. Saudi J Kidney Dis Transpl. 2016;27(2):270-80.

11. Barata NE. Dyadic relationship and quality of life patients with chronic kidney disease. J Bras Nefrol. 2015;37(3):315-22.

12. Basok EK, Atsu N, Rifaioglu MM, et al. Assessment of female sexual function and quality of life in predialysis, peritoneal dialysis, hemodialysis, and renal transplant patients. Int Urol Nephrol. 2009;41(3):473-81.

13. Baykan H, Yargic I. Depression, anxiety disorders, quality of life and stress coping strategies in hemodialysis and continuous ambulatory peritoneal dialysis patients. Klinik Psikofarmakoloji Bulteni. 2012:22(2):167-76.

14. Borowiak E, Braksator $E$, Nowicki M, et al. Quality of life of chronic hemodialysis and peritoneal dialysis patients. Clin Exp Med Lett. 2009. 50(1):37-42

15. Brown EA, Johansson L, Farrington $K$, et al. Broadening options for long -term Dialysis in the elderly (BOLDE): differences in quality of life on peritoneal dialysis compared to haemodialysis for older patients. Nephrol Dial Transplant. 2010;25(11):3755-63.

16. Chen JY, Wan EYF, Choi EPH, et al. The health-related quality of life of Chinese patients on hemodialysis and peritoneal Dialysis. Patient. 2017:1-10.

17. Czyzewski L, Sanko-Resmer J, Wyzgal J, et al. Assessment of health-related quality of life of patients after kidney transplantation in comparison with hemodialysis and peritoneal dialysis. Ann Transplant. 2014;19:576-85.

18. Fructuoso M, Castro R, Oliveira L, et al. Quality of life in chronic kidney disease. Nefrologia. 2011;31(1):91-6.

19. Goncalves FA, Dalosso IF, Borba JM, et al. Quality of life in chronic renal patients on hemodialysis or peritoneal dialysis: a comparative study in a referral service of Curitiba - PR. Jornal brasileiro de nefrologia. 2015;37(4):467-74.

20. Ibrahim N, Chiew-Tong NK, Desa A. Symptoms and health-related quality of life in patients with heamodialysis and continuous ambulatory peritoneal dialysis. Res J Med Sci. 2011;5(5):252-6.

21. Ikonomou M, Skapinakis $\mathrm{P}$, Balafa $\mathrm{O}$, et al. The impact of socioeconomic factors on quality of life of patients with chronic kidney disease in Greece. J Ren Care. 2015;41(4):239-46.

22. Kim JY, Kim B, Park KS, et al. Health-related quality of life with KDOOL-36 and its association with self-efficacy and treatment satisfaction in Korean dialysis patients. Qual Life Res. 2013;22(4):753-8.

23. Kontodimopoulos N, Pappa E, Niakas D. Gender- and age-related benefit of renal replacement therapy on health-related quality of life. Scand J Caring Sci. 2009;23(4):721-9.

24. Liu WJ, Musa R, Chew TF, et al. Quality of life in dialysis: a Malaysian perspective. Hemodial Int. 2014;18(2):495-506.

25. Maglakelidze N, Pantsulaia T, Tchokhonelidze I, et al. Assessment of healthrelated quality of life in renal transplant recipients and dialysis patients. Transplant Proc. 2011;43(1):376-9.

26. Nakayama $M$, Ishida $M$, Ogihara $M$, et al. Social functioning and socioeconomic changes after introduction of regular dialysis treatment and impact of dialysis modality: a multi-Centre survey of Japanese patients. Nephrology (Carlton). 2015;20(8):523-30.

27. Okpechi IG, Nthite T, Swanepoel CR. Health-related quality of life in patients on hemodialysis and peritoneal dialysis. Saudi J Kidney Dis Transpl. 2013;24(3):519-26

28. Ören B, Enc N. Quality of life in chronic haemodialysis and peritoneal dialysis patients in Turkey and related factors. Int J Nurs Pract. 2013; 19(6):547-56.

29. Ramos EC, Santos I, Zanini R, et al. Quality of life of chronic renal patients in peritoneal dialysis and hemodialysis. Jornal brasileiro de nefrologia. 2015; 37(3):297-305.

30. Tannor EK, Archer E, Kapembwa K, et al. Quality of life in patients on chronic dialysis in South Africa: a comparative mixed methods study. BMC Nephrol. 2017;18(1):4.

31. Theofilou P. Quality of life in patients undergoing hemodialysis or peritoneal dialysis treatment. J Clin Med Res. 2011;3(3):132-8.

32. Turkmen $K$, Yazici R, Solak Y, et al. Health-related quality of life, sleep quality, and depression in peritoneal dialysis and hemodialysis patients. Hemodial Int. 2012;16(2):198-206.

33. Watanabe $Y$, Ohno $Y$, Inoue $T$, et al. Home hemodialysis and conventional in-center hemodialysis in Japan: a comparison of health-related quality of life. Hemodial Int. 2014;18(Suppl 1):S32-8.

34. Wright LS, Wilson L. Quality of life and self-efficacy in three Dialysis modalities: Incenter hemodialysis, home hemodialysis, and home peritoneal Dialysis. Nephrol Nurs J. 2015;42(5):463-76.

35. Wu F, Cui L, Gao X, et al. Quality of life in peritoneal and hemodialysis patients in China. Ren Fail. 2013;35(4):456-9.

36. Yang F, Griva K, Lau T, et al. Health-related quality of life of Asian patients with end-stage renal disease (ESRD) in Singapore. Qual Life Res. 2015:24(9):2163-71.

37. Ying SC, Krishnan M. Interpretation of quality of life outcomes amongst end stage renal disease patients in selected hospitals of Malaysia. Int J Pharm Sci Res. 2014;5(1):60-9.

38. Yongsiri $\mathrm{S}$, Thammakumpee J, Prongnamchai $\mathrm{S}$, et al. The association between bioimpedance analysis and quality of life in pre-dialysis stage 5 chronic kidney disease, hemodialysis and peritoneal dialysis patients. J Med Assoc Thail. 2014;97(3):293-9.

39. Ware JE, Kosinski MM, Keller SD. A 12-item short-form health survey: construction of scales and preliminary tests of reliability and validity. Med Care. 1996:34:220-33.

40. Weisbord SD, Fried LF, Arnold RM, et al. Development of a symptom assessment instrument for chronic hemodialysis patients: the Dialysis symptom index. J Pain Symptom Manag. 2004;27(3):226-40.

41. Van der Willik EM, Leegte $M$, van Ittersum FJ, Prantl K, Bart HAJ, Dekker FW, Hemmelder $\mathrm{MH}$. First Dutch registry of patient-reported outcome measures (PROMS) has a low response in dialysis patients [abstract]. Nephrology Dialysis Transplantation. 2018:33(Suppl 1):i262.

42. Van der Willik EM, Meuleman Y, Prantl K, van Rijn G, Bos WJW, van Ittersum FJ, Bart HAJ, Hemmelder MH, Dekker FW. Patient-reported outcome measures: selection of a valid questionnaire for routine symptom assessment in patients with advanced chronic kidney disease - a fourphase mixed methods study. BMC Nephrology. 2019. Accepted. https://doi. org/10.1186/s12882-019-1521-9.

43. Ware JE. SF-36 Health Survey. Manual and Interpretation Guide; 1997.

44. Wyld M, Morton RL, Hayen A, et al. A systematic review and metaanalysis of utility-based quality of life in chronic kidney disease treatments. PLOS. 2012;9(9):1-10.

45. Gandek B, Ware JE, Aaronson NK, et al. Cross-validation of item selection and scoring for the SF-12 health survey in nine countries: results from the IQOLA project. J Clin Epidemiol. 1998;51:1171-8.

46. Loosman WL, Hoekstra T, van Dijk S, et al. Short-form 12 or short-form 36 to measure quality-of-life changes in dialysis patients? Nephrol Dial Transplant. 2015;30:1170-6

47. World Health Organization. ICD-10. Internationale statistische classificatie van ziekten en met gezondheid verband houdende problemen, tiende revisie. 2014.

48. ERA-EDTA codes mortality. https://www.nefrovisie.nl/wp-content/uploads/2 016/08/renine codes doodsoorzaak.pdf. Accessed 2 May 2019.

49. Bouwmans $\mathrm{C}$, Krol M, Severens $H$, et al. The iMTA productivity cost questionnaire a standardized instrument for measuring and valuing health -related productivity losses. Value Health. 2015;18(6):753-8. 
50. Institute for Medical Technology Assessment, Productivity and Health Research Group. Handleiding iMTA Medical Cost Questionnaire (iMCQ): iMTA, Erasmus University Rotterdam; 2018. https://www.imta.nl/ questionnaires/. Accessed 7 June 2016.

51. Hakkaart-van Roijen L, Van der Linden N, Bouwmans CAM, et al. Kostenhandleiding: Methodologie van kostenonderzoek en referentieprijzen voor economische evaluaties in de gezondheidszorg. Diemen: Zorginstituut Nederland; 2015

52. Versteegh MM, Vermeulen KM, Evers SMAA, et al. Dutch tariff for the five -level version of EQ-5D. Value Health. 2016;19:343-52.

53. Brooks R, Group E. EuroQol: the current state of play. Health Policy. 1996;37:53-72.

54. Eikelenboom N, van Lieshout J, Wensing M, et al. Implementation of personalized self-management support using the self-management screening questionnaire SeMaS; a study protocol for a cluster randomized trial. Trials. 2013;14(336):1-9.

55. Eikelenboom N, Smeele I, Faber M, et al. Validation of self-management screening (SeMaS), a tool to facilitate personalised counselling and support of patients with chronic diseases. BMC Fam Pract. 2015;16(165):1-12.

56. Lan PG, Clayton PA, Johnson DW, et al. Duration of hemodialysis following peritoneal dialysis cessation in Australia and New Zealand: proposal for a standardized definition of technique failure. Perit Dial Int. 2016:36:623-30.

57. Hall $\mathrm{YN}$, Larive $\mathrm{B}$, Painter $\mathrm{P}$, et al. Effects of six versus three times per week hemodialysis on physical performance, health, and functioning: frequent hemodialysis network (FHN) randomized trials. Clin J Am Soc Nephrol. 2012;7:782-94.

58. Lowrie EG, Curtin RB, LePain N, et al. Medical outcomes study short form-36: a consistent and powerful predictor of morbidity and mortality in dialysis patients. Am J Kidney Dis. 2003;41(6):1286-92.

59. Korevaar JC, Jansen MAM, Merkus MP, et al. Quality of life in predialysis end-stage renal disease patients at the initiation of dialysis therapy. Perit Dial Int. 2000;20:69-75.

60. Dolan P. Modeling valuations for EuroQol health states. Med Care. 1997; 35(11):1095-108.

61. Walters SJ, Brazier JE. Comparison of the minimally important difference for two health state utility measures: EQ-5D and SF-6D. Qual Life Res. 2005;14:1523-32.

62. Culleton BF, Walsh M, Klarenbach SW, et al. Effect of frequent nocturnal hemodialysis vs conventional hemodialysis on left ventricular mass and quality of life. JAMA. 2007;297(11):1291-9.

63. Jardine MJ, Gray NA, De Zoysa J, et al. Design and participant baseline characteristics of 'a clinical trial of IntensiVE Dialysis': the ACTIVE Dialysis study. Nephrology. 2015;20:257-65.

64. Korevaar JC, Feith GW, Dekker FW, et al. Effect of starting with hemodialysis compared with peritoneal dialysis in patients new on dialysis treatment: a randomized controlled trial. Kidney Int. 2003;64:2222-8.

\section{Publisher's Note}

Springer Nature remains neutral with regard to jurisdictional claims in published maps and institutional affiliations.

Ready to submit your research? Choose BMC and benefit from:

- fast, convenient online submission

- thorough peer review by experienced researchers in your field

- rapid publication on acceptance

- support for research data, including large and complex data types

- gold Open Access which fosters wider collaboration and increased citations

- maximum visibility for your research: over $100 \mathrm{M}$ website views per year

At $\mathrm{BMC}$, research is always in progress.

Learn more biomedcentral.com/submissions 